\title{
The Announcement Effect: Evidence from Open Market Desk Data ${ }^{1}$
}

\author{
by \\ Selva Demiralp ${ }^{*}$ and Oscar Jordá**
}

June 2001

\begin{abstract}
This paper investigates the ability of the Federal Reserve to manipulate the overnight rate without open market operations (which Demiralp and Jorda (2000) term the announcement effect), using high-frequency, open-market-desk data. Using similar data, Hamilton (1997) takes advantage of forecast errors in the Treasury balance to compute the elasticity of the federal funds rate to these errors and thus to obtain a measure of the liquidity effect. Similarly, one can view daily deviations of the federal funds rate from target as forecast errors in the reserve need (see Taylor, 2000). By analyzing the manner and the type of operation the Fed uses to maintain the federal funds rate close to its targeted value and by observing the pattern of operations on the days surrounding a change in this target, we provide evidence of the announcement effect. Furthermore, we show that the discipline of the FOMC schedule dictates, not only the process of expectations formation in the overnight rate, but also the price adjustment process of term rates.
\end{abstract}

Keywords: open market operations, announcement effect, term structure.

JEL Codes: E5, E4, C5

*Selva Demiralp

Board of Governors of the Federal Reserve

Division of Monetary Affairs

Washington, DC 20551

e-mail: selva.demiralp@frb.gov

** Oscar Jordá

U. C. Davis

Dept. of Economics

One Shields Ave.

Davis, CA 95616-8578

e-mail: ojorda@ucdavis.edu

\footnotetext{
${ }^{1}$ This paper was prepared for the Federal Reserve Bank of New York Conference "Financial Innovation and Monetary Transmission," April 4-5, 2001. We would like to thank Sherry Edwards, David Lindsey, Athanasios Orphanides and the seminar participants at the Board of Governors for valuable comments on an earlier draft. We are grateful to Kenneth Kuttner, and Charles Evans for their patience and support. The opinions expressed are those of the authors and do not necessarily reflect the views of the Board of Governors of the Federal Reserve System or other members of its staff.
} 


\section{Introduction}

The textbook view of the monetary transmission mechanism rests on the central bank's ability to manipulate the overnight interest rate via its monopolistic control of the supply of reserves followed by some form of rational expectations mechanism that ensures movements in the overnight rate appropriately reverberate into longer maturity rates. However, while there is little disagreement that the central bank effectively controls the overnight rate, the notion that it does so via a liquidity effect and the nature of term structure relations need to be revised.

Modern central banking is characterized, at a minimum, by public announcements of an interest rate target (such as the federal funds rate target in the U.S.), sometimes, by additionally disclosing an inflation target (such as the Bank of Australia, and the Bank of England), and in the extreme, by making the parameters of the policy reaction function publicly available (such as the Reserve Bank of New Zealand). This constitutes a significant departure from traditional central banking.

Why have central banks abandoned their recalcitrant secretive behavior in favor of these public disclosures about their policy moves? It is natural to conjecture that the reasons may include better and more precise control of the overnight rate, but probably and more importantly, better communication on future policy moves: in essence, the holy grail of controlling long rates by manipulating expectations as well.

This paper investigates these issues for the U.S. Federal Reserve. In particular, we focus on the effect that the 1994 new policy of announcing the targeted level of the federal funds rate had on the liquidity effect and the manner the Fed uses open market operations to control the federal funds market. Moreover, we want to investigate what effect, if any, did this change in policy have on the behavior of the term structure.

Up until the February 3-4, 1994 Federal Open Market Committee (FOMC) meeting, monetary policy objectives for the federal funds rate and the outcome of the FOMC meeting itself, were never announced and had been kept confidential. ${ }^{2}$ Subsequent to the 1994 policy change to disclose the new targeted level for the federal

\footnotetext{
${ }^{2}$ However, Demiralp and Jorda (2000) argue that perhaps as early as mid-November 1989, there was little if any ambiguity in decoding any changes in the federal funds rate target on the basis of the pattern of open market operations that followed the meeting. Their evidence mainly consists on the fact that the prime rate was typically adjusted within a day or two of an unannounced federal funds rate target change.
} 
funds rate, and inspired by similar developments in other central banks, the papers by Demiralp and Jordá (2000), Guthrie and Wright (2000), Taylor (2000), Thornton (2000) and Woodford (2000), investigate a central bank's ability to control the overnight rate, not merely with traditional open market operations, but by effectively communicating the desired level of the overnight rate and standing ready to enforce that level. According to Meulendyke (1998), "The [federal funds] rate has tended to move to the new preferred level as soon as the banks know the intended rate..." In this paper we term this way of controlling the overnight rate as the announcement effect (following Demiralp and Jordá, 2000) and it differs from the conventional liquidity effect in that the volume of open market operations required to achieve the new targeted level is substantially smaller because of expectations.

The strategy we pursue to investigate the announcement effect consists on using two types of control. The first is to analyze the data with two primary sub-samples: one predating and the other postdating the 1994 policy change. The second is to compare, within sub-sample, the pattern of open market operations surrounding days in which the target was changed relative to the rest of the sub-sample.

Most of the time, open market operations carried by the Trading Desk at the Federal Reserve Bank of New York (or the Desk for short) are designed to accommodate variations in the reserve need that stem from a variety of factors (such as changes in currency holdings, float, large Treasury balances, etc.), to manage currency in circulation, and other variations in the reserve supply. Based on a particular type of such variations (unexpectedly large Treasury balances), Hamilton (1997) calculates the interest rate elasticity to an unanticipated reserve shortfall. In this paper, we measure the elasticity of different types of open market operations to variations in the reserve need, expectations of a target change and enforcement of a new target level instead.

The expectation that policy decisions on whether to change the federal funds rate target will typically follow FOMC meetings introduces a natural discipline in term rates, and more specifically, in the manner expectations on future rates are updated according to the FOMC calendar. Consequently, we investigate whether indeed the market follows this discipline and whether the response of term rates on the FOMC calendar is consistent with the rational expectations hypothesis of the term structure. 
The paper is organized as follows. Section 2 describes the nature of the announcement effect and the role of expectations in the context of a simple model of the reserves market proposed by Taylor (2001). Based on the insights of this model, deviations of the federal funds rate from its targeted value emerge as indicators of the Desk's forecast error of the reserve need. These deviations can therefore be used to asses how the Desk manages different types of open market operation to maintain the funds rate on target, as well as to signal changes in this target. Thus, Section 3 reviews the behavior of the deviation of the funds rate from target over the maintenance period while Section 4 presents detailed evidence of the emergence of the announcement effect since 1994. The same mechanism that ties the formation of expectations around the FOMC calendar and gives rise to the announcement effect determines the behavior of term interest rates. Section 5 documents how movements in term rates are closely tied to the expectations formation associated to the FOMC calendar. Section 6 summarizes the main findings and concludes.

\section{The Federal Funds Market and Open Market Operations}

The stylized model of the reserves market (described for example in Gilbert, 1985, Heller, 1988, and Goodfriend and Whelpey, 1993) describes a downward sloping demand schedule of reserves as a function of the federal funds rate. This relation reflects the demand for reservable deposits on behalf of depository institutions and therefore, reserve requirements and excess reserves. The supply of reserves is depicted as a kinked schedule: a perfectly inelastic supply of reserves section corresponding to the level of nonborrowed reserves determined by open market operations, and an upward sloping section corresponding to discount window borrowing. The slope of the latter section of the supply schedule is characterized by the spread between the discount rate and the federal funds rate along with the administrative costs of having tapped a resource that is directly rationed by the corresponding regional Federal Reserve Bank. Under this simple framework, an open market sale has the effect of reducing nonborrowed reserves, thus shifting the supply schedule to the left, and increasing the equilibrium level of the federal funds rate along with the amount of discount window borrowing. 
Recent developments in the reserves market require that we refine this canonical model. First, the collapse of the Continental Illinois Bank and Trust Company and other similar failures in the mid-eighties has made banks significantly more reluctant to use the discount window (although extended credit reached volumes in excess of $\$ 7$ billion at the height of the crisis, this volume has remained essentially at zero levels throughout the nineties). As a consequence, the supply of reserves is now better characterized by its inelastic section, which is determined by nonborrowed reserves alone.

Secondly, banks hold reserves primarily for two reasons: (i) to meet legal reserve requirements, and (ii) to facilitate interbank payments. Reductions in reserve requirements (in 1990, and 1992), along with a clarification of Fed policy and advances in computer technology that since 1994 have encouraged banks to be more aggressive in "sweeping" customer deposits subject to reserve requirements into instruments exempt from such requirements (see Anderson and Raasche, 2000), have significantly reduced reserve requirements (from $\$ 20$ billion in 1990, to \$10 billion in 1996 and to $\$ 4$ billion today). However, banks still need reserves to meet interbank payments and to meet the demand for currency. Thirdly, and more importantly, since the February 3-4, 1994 FOMC meeting, the Fed has publicly disclosed its targeted level for the federal funds rate. This has had a significant effect on the process of price discovery in the federal funds market and on the manner the market forms expectations about future policy moves.

The emphasis on the rising role of expectations in the reserves market is highlighted in a recent paper by Taylor (2000). The federal funds market is essentially a “double auction" market in which buyers and sellers ask different prices on overnight loans. Thus, the effective federal funds rate is a volume weighted average of rates on trades reported by brokers. The Fed does not directly trade in the federal funds market but controls the amount of reserves by trading in the repo (RP) and Treasury markets, typically once a day, in the morning (since April 5, 1999, the Trading Desk enters the market during a 10 minute interval around 9:30 am). On the other hand, trading in the federal funds market concentrates near to the closing for the day. 
Banks meet their legal reserve requirements on an average over a two-week period called the maintenance period. Prior to August $18,1998^{3}$ the calculation of the requirement was done concurrently with the maintenance period, and was known as contemporaneous reserve accounting (CRA). As we shall see, this induced substantial volatility in the federal funds rate in the final days of the maintenance period. However, since 1998, the Fed has reverted to computing the requirement over a two-week period that precedes the maintenance period (the maintenance period starts 30 days after the start of the corresponding 14-day computation period, see Clouse and Dow, 2000). This practice is termed lagged reserve accounting (LRA) and it has eliminated any contemporaneous elasticity of reserve requirements to the interest rate. However, notice that reserve requirements have been decreasingly important in explaining a bank's desire to hold reserves relative to reserves needed to clear interbank balances.

The motivation behind Taylor's (2001) model is the observation that changes in the target may affect the federal funds rate even without open market operations. This effect requires the credibility that the Trading Desk will appropriately react to any substantial deviations of the federal funds rate from target. In order to focus the discussion on the announcement effect and with the disclaimer that any model of the federal funds market is at best, a rough approximation of the complexities in this market, Taylor (2001) describes the demand for reserves ${ }^{4}$ as

$$
R_{t}^{d}=-\alpha\left(f_{t}-\gamma E_{t} f_{t+1}\right)+\varepsilon_{t}, \quad \alpha, \gamma>0
$$

where $R_{t}^{d}$ is the stock of reserve balances, $f_{t}$ is the effective funds rate, $\varepsilon_{t}$ is a demand shock, and $E_{t}$ is the conditional expectation operator based on information available up to time $t$. The specification in (1) can be understood as describing within maintenance period bank behavior and abstracts from other direct demand factors (such as other

\footnotetext{
${ }^{3}$ Although the date of the actual change in policy is July 1998, because there is a 30-day delay from the computation period to the maintenance period, the first maintenance period that effectively reflected the new policy was the 8/13/1998 to 8/26/1998 maintenance-period. It should also be emphasized that the Fed had experimented with LRA in the past but prior to the beginning of our sample.

${ }^{4}$ For a more detailed model of the demand for reserves see the papers by Clouse and Dow (2000), and Bartolini, Bertola and Prati (1999).
} 
determinants of client demand for deposits) that are likely to influence reserve demand across maintenance periods.

Equation (1) is a rational expectations setting in which the demand for reserves is now a function of the expected federal funds rate: that is, changes in the effective rate lead to movements along the demand curve but changes in the expected rate lead to shifts in the demand schedule, thus eliminating any arbitrage opportunities.

When the Federal Reserve is more open about current policy actions and future goals, the process of expectations formation about future policy actions gets more accurate and reliable: the timing of the change is tied down by the dates of FOMC meetings (with a few exceptions since 1994), and the magnitude of the change is usually a toss between a one quarter and a one half percentage points change (the norm since 1994 except for one 75 percentage point change). Therefore, one would expect the demand for reserves to adjust in anticipation of the forthcoming policy move. This shift in demand may or may not be then offset by the Federal Reserve.

The supply of reserves in Taylor's (2001) model is defined as a function of the gap between the effective federal funds rate and the target rate, $f_{t-1}^{*}$

$$
R_{t}^{s}=R_{t-1}+\beta\left(f_{t-1}-f_{t-1}^{*}\right), \beta>0
$$

Accordingly, the Federal Reserve changes the reserve supply for two reasons: (i) to accommodate an unexpected variation in the reserve need (i.e. whenever the funds rate is expected to deviate from the given target), or (ii) for a given level of the funds rate, to adjust the pressure in the reserves market in a manner consistent with a new target level. Orphanides (2001) has suggested that (2) may be too simple a specification of the supply curve. Among other things, it is perhaps more realistic to describe the Fed as actually forecasting the reserve need on the basis of $E_{t-1}\left(f_{t}\right)-f_{t-1}^{*}$ rather than reacting to past deviations $f_{t-1}-f_{t-1 .}^{*}$. However, for the purposes of our discussion, there is little loss in proceeding with Taylor's original specification, leaving for future work alternative variations on expression (2).

Figure 1 describes the role of expectations and the behavior of interest rates in the reserves market. This figure depicts the usual, downward sloping demand schedule and 
an inelastic supply schedule set at the level of nonborrowed reserves (NBR) (following our discussion that there is almost zero discount window borrowing at present). In this figure, we consider three mechanisms by which the federal funds rate target increases from $f_{0}^{*}$ to $f_{1}^{*}$. The first scenario describes the traditional story: there is no anticipation of the policy actions and the Federal Reserve has to signal the entire target change through open market operations by cutting down reserves from $N B R_{0}$ to $N B R_{1}{ }^{\text {old }}$.

The second and the third scenarios consider the role of expectations in the reserves market. When the market anticipates an increase in the target, it is more profitable for the banks to borrow prior to the announcement and then lend after the announcement, which leads to a shift of the demand curve to the right before the announcement, from $D_{0}$ to $D_{1}$. Note that the corresponding intermediate change in the equilibrium funds rate from $f_{0}^{*}$ to $f_{0}$ is independent of any open market operations, and is purely due to the anticipation of the new target level.

The Federal Reserve can respond to this shift in expectations in two ways: (i) by accommodating and thus temporarily offsetting the expectational demand shift to $D_{1}$ so that the federal funds rate is kept at the present level, $f_{0}^{*}$, or (ii) by remaining inactive and allowing the federal funds rate to rise in anticipation of the target change. If the Fed accommodates in anticipation of an increase in the federal funds rate, the Desk will actually expand (rather than contract) reserves to the level $N B R_{0}{ }^{*}$ before contracting to the level $N B R_{1}{ }^{\text {new }}$. Whether or not the Fed decides to accommodate, the better the market anticipates the Fed's actions, the smaller the contraction from $N B R_{0}$ to $N B R_{1}{ }^{\text {new }}$, i.e., the Fed requires a smaller volume of open market operations to signal the market of an increase in the federal funds rate which is the essence of the announcement effect.

\section{Preliminary Considerations: Deviations of the Federal Funds Rate from Target}

The empirical analysis we perform below will use the deviation of the effective federal funds rate from the targeted level during the previous day as an indicator of reserve imbalances. Changes in the target are typically announced around 2:15 pm EST, after open market operations for that day have been already executed. Conditional on other 
factors, the response of open market operations to these imbalances gives us an indirect measure of the liquidity effect. Let $f_{t}$ denote the federal funds rate and let $f_{t}^{*}$ denote the target, the variable we explore is therefore, $\left(f_{t-1}-f_{t-1}{ }^{*}\right){ }^{5}$ Recall that the Fed typically executes open market operations in the morning whereas most of the trading in the federal funds market takes place near the closing of the trading day. Therefore, deviations of the federal funds rate from target can be interpreted as forecast errors in the reserve need for that day. This argument certainly characterizes the majority of our sample up to August 18, 1998, when the Fed switched from contemporaneous reserve accounting (CRA) to lagged reserve accounting (LRA). After the change to LRA, uncertainty regarding reserve requirements was virtually eliminated although uncertainty regarding balances for transactions purposes still remained.

To get a better sense of the persistence of this forecast error (or in other words, how quickly it is eliminated) and the effects of the "seasonality" of the maintenance period on both the magnitude and the dynamics of $\left(f_{t-1}-f_{t-1}{ }^{*}\right)$, we experiment with the following specification:

$$
f_{t}-f_{t}^{*}=\alpha_{t}+\rho_{1 t}\left(f_{t-1}-f_{t-1}^{*}\right)+\rho_{2 t}\left(f_{t-2}-f_{t-2}^{*}\right)+\beta \Delta f_{t}^{*}+\varepsilon_{t}
$$

i.e., a second order autoregression where the parameters are allowed to vary according to the day of the maintenance period, ${ }^{6}$ except for $\beta$ since $\Delta f_{t}{ }^{*}$, which denotes a change in the target on date $t$, is nonzero only when the target is changed. Equation (3) is estimated over 3 different samples: April 25,1984 to February 4, 1994; February 4, 1994 to August 17, 1998, and August 18, 1998 to August 14, 2000. These sub-samples correspond to the period prior to the policy of announcing the target, the period after that change in policy

\footnotetext{
${ }^{5}$ Hamilton (1997) uses open market data to estimate the liquidity effect by carefully calculating the effect of surprises in the Treasury balance on the federal funds rate. The requisite that this surprise component be as accurately measured as possible required him to be extremely detailed in modeling all the sources of seasonality relating to the Treasury balance and the other components of the Fed's balance sheet - in essence, he is trying to capture the manner the Fed constructs its forecasts. However, because the variable of interest, $\left(f_{t-1}-f_{t-1}{ }^{*}\right)$, is directly observable rather than computed, we are able to dispense with such complications.

${ }^{6}$ Specifically, $\alpha_{t}=\sum_{j=1}^{10} \alpha_{j} d_{t}^{j}, \rho_{i t}=\sum_{j=1}^{10} \rho_{i}^{j} d_{t}^{j}$ for $i=1,2$ and where $d_{t}^{\mathrm{j}}=1$ if observation $t$ belongs to the $j^{\text {th }}$ day of the maintenance period for $j=1,2, \ldots, 10$ (since we only need to consider business days); and is 0 otherwise.
} 
with CRA, and the period in which the Fed switched from CRA to LRA. Figure 2 displays the variation in this average deviation and its persistence as a function of the day of the maintenance period for these three samples. ${ }^{7}$

The average deviation of the federal funds rate from target is significantly higher (up to 20 basis points on average) on the last day of the maintenance period for the first two sub-samples. However, notice that since reserve accounting was modified from CRA to LRA, this average deviation has dwindled to essentially zero. Deviations from target also tend to be lower on Fridays. This observation is consistent with Hamilton (1996) and Clouse and Dow (2000) who argue that, although for different reasons, reserves on Fridays are relatively more expensive. The dynamic pattern of these deviations has also changed substantially across samples. It is most persistent in the first sample, and toward the final days of the maintenance period. These observations are consistent with the high volatility the federal funds rate typically exhibits during the last days of the maintenance period. It is safe to say that over time, the Fed has managed to reduce the average deviations from target and it has reduced the length of time it takes to eliminate these perturbations.

The estimates of $\beta$ in (3) provide suggestive evidence regarding how well target changes are forecast. For each of the three sub-samples, these estimates (with standard errors in parenthesis) are: $0.59(0.12), 0.37(0.17)$, and $0.43(0.17)$, respectively. If target changes were completely unexpected, the coefficient on the variable $\Delta f_{t}^{*}$ would be close to 1 in value. This hypothesis is clearly rejected in all sub samples but perhaps more importantly, the decrease of this coefficient from 0.59 to 0.37 , after the policy of announcing target changes was introduced, is statistically significant. This shift suggests that expectations on policy moves may have improved after 1994, an issue we explore in more detail in the next section.

\footnotetext{
${ }^{7}$ For a more detailed investigation of the behavior of the federal funds rate and the interbank market, see the papers by Bartolini, Bertola and Prati (2000), and Furfine (2000).
} 


\section{The Announcement Effect versus the Liquidity Effect}

This section investigates the manner in which the Trading Desk juggles different types of open market operations in response to variations in the reserve need and, more importantly, to changes in the federal funds rate target. In particular, we want to address the following two questions:

1. Is there evidence that since the 1994 change in policy, the liquidity effect has been complemented with the announcement effect and that therefore, there is an appreciable difference in the type and size of operations needed to achieve the new, targeted level for the federal funds rate?

2. Are there any differences in the portfolio of operations done during days when the target is changed relative to other days?

The second question complements the first one in that differences in the portfolio of operations during target day changes may help corroborate or disavow whether in fact the Fed is any more responsive to these changes than it is to variations in the reserve need. The sample period that we investigate extends from April 25, 1984 to August 14, 2000 and includes 115 changes in the target. This sample is split first, with the February 4, 1994 decision by the Fed to publicly announce any changes to the federal funds rate target, and second, with the August 18, 1998 decision to move from CRA to LRA.

\subsection{The Endogenous Variables: Types of Open Market Operations and Transformations}

The available open market data consists of ten different types of operation, which can be roughly grouped according to whether the operation injects or drains liquidity and according to the relative degree of permanency of the operation. Table 1 classifies these data with the mentioned criteria and assigns the acronyms we will use in the paper, namely, PB, TB, and $\mathrm{OB}$ for permanent, temporary and overnight purchases (which add liquidity); and PS, TS, and OS for permanent, temporary and overnight sales (which drain 
liquidity). This way of grouping the different types of operation affords us more degrees of freedom at little cost: although the Fed does not consider domestic and foreign purchases as complete substitutes (chiefly because of the clarity of the signal that they deliver to the market with the former tool) they certainly fulfill different liquidity needs relative to shorter-term operations. ${ }^{8}$

Each of these operations needs to be further transformed before we initiate our analysis. We begin by standardizing the volume of each type of operation by the volume of total reserves held during the maintenance period prior to when the operation is executed. The purpose of this normalization is to filter trends in the volume of reserves (such as the increase in the demand for currency described above). The second transformation is motivated by reserve accounting practices and the differing effects operations have according to type and according to when they are executed within the maintenance period.

Following Feinman (1993), we adjust temporary and overnight operations according to the number of days spanned by the transaction (adjusting for weekends and holidays) and then dividing by the number of days in the maintenance period (14). ${ }^{9}$ If the temporary transaction spans beyond the maintenance period, then we adjust by the number of days left in the current maintenance period. Because we normalize by the volume of total reserves in the preceding maintenance period, temporary transactions that spill over adjacent maintenance periods have the reverse effect during the maintenance period in which they mature.

For instance, a normalized $0.1^{10}$ matched sale-purchase with a four-day maturity (i.e. generically a temporary sale (TS) in our terminology) executed Tuesday of the second week of the maintenance period, has the effect of lowering the normalized volume of reserves by $2 / 14$ of 0.1 . At its maturity, Friday of the first week of the following maintenance period, it will raise the normalized volume of liquidity by $12 / 14$ of 0.1 (assuming the level of total reserves has remained constant over the two maintenance

\footnotetext{
${ }^{8}$ Appendix A.1 describes the details of how the Trading Desk at the Federal Reserve Bank of New York actually implements open market operations.

${ }^{9}$ Note that an overnight transaction executed on a Friday is not reversed until Monday and, therefore, its effect on the maintenance-period average volume of reserves is that of a three-day transaction instead.

${ }^{10}$ Note that the normalization eliminates the unit of measurement in favor of expressing liquidity as a fraction of the volume of reserves in the previous maintenance period.
} 
periods, leaving the normalization unaffected). It is important to highlight that the effect of this matched sale-purchase during the maintenance period in which it matures forms part of the information set available when the operation is executed. Consequently, an increase in the forecast for the reserve need may not prompt the Fed to inject liquidity if several of these temporary transactions are slated to mature during that maintenance period. Similarly, outright operations are assumed to be reversible only by a counterpart outright transaction and consequently, they are considered permanent. Therefore, they are adjusted by the number of days left in the maintenance period as well. Each type of operation normalized with the procedure described above will be collected in the vector $\boldsymbol{X}_{t}=\left(P B_{t}, T B_{t}, O B_{t}, P S_{t}, T S_{t}, O S_{t}\right)^{\prime}$

\subsection{The Explanatory Variables: Decomposing the $f_{t}-f_{t}^{*}$ Deviations}

The empirical strategy requires that we analyze the motivation behind the different types of open market operation the Desk chooses to execute in any given day. As we have seen, the Desk may intervene in the market for several reasons: (i) to accommodate shocks in the demand for reserves in order to maintain the federal funds rate aligned with the target, (ii) to accommodate expectations of future target changes reflected in the demand for reserves, and (iii) to enforce a new target level. Accordingly, we argued in Section 2 that the most natural candidate explanatory variable is the deviation of the federal funds rate from target, $\left(f_{t}-f_{t}^{*}\right)$. However, in order to separate each of the motivations (i)-(iii) above, we refine this deviation into three components,

$$
\begin{aligned}
& \operatorname{NEED}_{t} \equiv f_{t}-\left[f_{m(t)-1}^{*}+w_{t} E_{m(t)-1}\left(\Delta f_{m(t)}^{*}\right)\right] \\
& \operatorname{EXPECT}_{t} \equiv E_{m(t)-1}\left(\Delta f_{m(t)}^{*}\right) \\
& \operatorname{SURPRISE} E_{t} \equiv \Delta f_{t}^{*}-E_{m(t)-1}\left(\Delta f_{m(t)}^{*}\right)
\end{aligned}
$$

The time subscript $m(t)$ denotes the maintenance period $m$ to which observation $t$ belongs.

Therefore $f_{m(t)-1}^{*}$ denotes the value of the target at the start of the maintenance period to 
which observation $t$ belongs, $w_{t}$ denotes the relative probability that a target change occurs in day $t$ of the current maintenance period, and $E_{m(t)-1}\left(\Delta f_{m(t)}^{*}\right)$ denotes expectations of a target change for the maintenance period to which observation $t$ belongs, conditional on information available at the beginning of the maintenance period. Consequently, the variable $N E E D$ is designed to proxy for reserve projections and reflects variations in the approximated reserve need per se, but factoring expectations of a target change. Note that expectations of a target change are formed at the beginning of the maintenance period rather than daily (which is the type of expectation we explore in Section 5) since we are interested in learning how those expectations affect the average volume of reserves over the maintenance period. The weights $w_{t}$ then assign each day of the maintenance period the probability that the expected target change will be realized on that particular day. These weights correspond to the empirical frequency of the distribution of target changes over the maintenance period.

The variable EXPECT denotes the beginning of the maintenance period expectation of a change in the target rather than a one-day ahead forecast. Therefore, this variable reflects the Fed's willingness to accommodate or profit from these movements in anticipation of a target change. Finally, the variable SURPRISE takes the value of zero except when the target is changed, in which case, it measures the portion of a target change that was unexpected. This term will therefore capture the response of open market operations designed to enforce the new target level and would most closely correspond in interpretation to the traditional mechanism that characterizes the liquidity effect. Equation (4) implies that the sum of the NEED, EXPECT, and SURPRISE variables is equivalent to:

$$
\left(f_{t}-f_{m(t)-1}^{*}\right)+\left(\Delta f_{t}^{*}-E_{m(t)-1}\left(\Delta f_{m(t)}^{*}\right)\right.
$$

which roughly corresponds to $f_{t}-f_{t}^{*}$ : since the target is changed infrequently, the second term in parenthesis is zero most of the time except to capture the unexpected component of a target change.

The variables described in equation (4) require that we formulate forecasts of future target changes at a maintenance period frequency rather than from one day to the 
next. Two options were natural at this point. The first was to measure expectations directly from the federal funds futures market as is done in Kuttner (2000). However, this strategy proved inadequate for two reasons: (i) data on the futures market is not available before 1989, and (ii), we wanted maintenance period forecast horizons rather than daily forecasts - a target change in any day of the maintenance period will affect the average volume of reserves over the period and not just for that particular date. The second option available was to use the forecasting models used in Demiralp and Jordá (2000), which are based on the autoregressive conditional hazard model (ACH). The $\mathrm{ACH}$ methodology allowed us to produce forecasts at a maintenance period frequency starting with the April 25-May 9, 1984 maintenance period. The appendix provides a brief description of the $\mathrm{ACH}$ model along with the specifications we used to construct the forecasts. A more detailed discussion of the model is beyond the scope of this paper and can be found in Hamilton and Jordá (2000) and Demiralp and Jordá (2000).

\subsection{Modeling Open Market Operations}

The transformations of the variables described in the preceding sections allow us to analyze the determinants of each type of open market operation contained in the vector $\boldsymbol{X}_{t}$. The Desk engages in open market operations approximately $60 \%$ of the time However, even the most common type of open market operation (OB) is used only about $35 \%$ of the time. Consequently, estimation of the Desk's choice of operation cannot be done with conventional estimators since the dependent variable remains unchanged during most days in the sample. In addition, one could view a "sale" operation as the negative of a "purchase" operation, and thus lump operations together according to their maturity (a similar strategy is adopted in Feinman, 1993). We preferred to maintain each type of operation separate to allow for the possibility that the Fed reacts asymmetrically.

Therefore, let $x_{k t}{ }^{*}$ denote the latent level of the $k^{\text {th }}$ type of open market operation, which is an element of $\boldsymbol{X}_{t}$, and let $\boldsymbol{z}_{t}$ contain 3 lags of all the elements of $\boldsymbol{X}_{t \cdot}{ }^{11}$ If this latent index $x_{k t}{ }^{*}$ were observable, it would be natural to specify its model as,

${ }^{11}$ That is, $z_{t}==\left(x_{P B, t-1}, x_{T B, t-1}, \ldots, x_{O S, t-1}, \ldots, x_{P B, t-3}, x_{T B, t-3}, \ldots, x_{O S, t-3}\right)$. 


$$
\begin{gathered}
x_{k t}^{*}=\alpha_{t}+\pi^{\prime} \mathbf{z}_{t}+\gamma_{t}^{N} \operatorname{NEED}_{t-1}+\gamma_{t}^{E} \text { EXPECT }_{t-1}+ \\
\gamma_{0}^{S} \text { SURPRISE }_{t}+\gamma_{1}^{S} S U R P R I S E_{t-1}+\gamma_{2}^{S} S U R P R I S E_{t-2}+\gamma_{3}^{S} S U R P R I S E_{t-3}+\varepsilon_{k t}
\end{gathered}
$$

where the coefficients on the NEED and EXPECT variables are allowed to vary according to the day of the maintenance period. ${ }^{12}$ However, we do not in fact observe $x_{k t}{ }^{*}$ but rather $x_{k t}$, whose values are determined by the following condition,

$$
x_{k t}=\left\{\begin{array}{ccc}
0 & \text { if } & x_{k t}^{*} \leq c_{k} \\
x_{k t}^{*} & \text { if } & x_{k t}^{*}>c_{k}
\end{array}\right.
$$

Expression (7) makes explicit that the minimum size of an operation of the $k^{\text {th }}$ type is $c_{k}$, otherwise the Fed does not engage in that operation and $x_{k t}=0$. Equation (6) describes the latent process for the $k^{\text {th }}$ type of open market operation, $x_{k t}{ }^{*}$ as a function of reserveneed forecast errors, changes in the target, expectations of such target changes, and other open market operations conducted in previous days. From the econometric point of view, equations (6) and (7) constitute a truncated regression. Under the assumption that the errors are normally distributed, this model can be estimated as a standard tobit model (see Maddala, 1983). ${ }^{13}$

The specification in equations (6) and (7) is quite flexible. In particular, the coefficient $\alpha_{t}$ modifies the threshold $c_{k}$ so that the minimum size of the $k^{\text {th }}$ operation is allowed to vary over the maintenance period. The inclusion of three lags of all the variables in $\boldsymbol{X}_{t}$ ensures the effect of the explanatory variables is measured independently of any predictable response to previous open market operations but it also serves to measure whether certain types of operation can be viewed as complements or substitutes

${ }^{12}$ Specifically, $\alpha_{t}=\sum_{j=1}^{10} \alpha_{j} d_{t}^{j}, \gamma_{t}^{N}=\sum_{j=1}^{10} \gamma_{j}^{N} d_{t}^{j}$ and $\gamma_{t}^{E}=\sum_{j=1}^{10} \gamma_{j}^{E} d_{t}^{j}$ where $d_{t}^{j}=1$ if observation $t$ belongs to the $j^{\text {th }}$ day of the maintenance period and is zero otherwise (note, $j=1,2, \ldots, 10$ ).

${ }^{13}$ In particular, denoting with $\phi_{t}$ and $\Phi_{t}$ the normal density and the distribution function respectively of observation $t$, the $\log$-likelihood can be expressed as: $\log L=\sum \log \left(1-\Phi_{t}\right)+\sum \log \phi_{t}$ where the first summation is over all the observations in which $x_{k t}=0$ and the second summation is over the remaining observations. 
of the $k^{\text {th }}$ type of operation. For example, in response to a reserve shortage, the Fed may react with a combination of overnight and temporary purchase operations and it may delay any sale operations it had planned. The coefficient on the lag value of the variable $N E E D$ varies according to the day of the maintenance period to reflect the possibility that the Fed may be more reluctant to intervene in the market certain days of the period relative to others. A similar motivation justifies the variation in the coefficient on the variable EXPECT. Finally, note that the variable SURPRISE enters contemporaneously and with up to three lags to measure how quickly after the announcement does the Fed need to signal the new level with open market operations. ${ }^{14}$ A strong liquidity effect would suggest that the parameters $\gamma_{I}^{S}$ are statistically significant and negative for open market purchase operations, and statistically significant and positive for open market sale operations. If these parameters are not statistically significant, we interpret this as evidence in favor of the announcement effect. The next subsection reports the outcome of these experiments.

\subsection{Results}

Table 2 contains a graphical summary of the signs of the coefficients associated with the NEED, EXPECTED, and SURPRISE variables across samples and for the regressions involving the purchase operations only. ${ }^{15}$ Table 3 contains a graphical summary of the signs of the cross correlations at different lags among the elements of $\boldsymbol{X}_{\boldsymbol{t}}$, also broken down by sample. In particular, $++/+(--/-)$ indicates a positive (negative) parameter that is significant at the $95 \% / 90 \%$ confidence level. A “.” Indicates a coefficient that is not statistically significant. Tables 4 and 5 contain the coefficient estimates and standard errors for the SURPRISE regressors for both the purchase and the sale operations.

\footnotetext{
${ }^{14}$ Unlike some of the previous regressors, note that this variable is zero for every day in the sample except when the target is changed.

${ }^{15}$ Due to the low frequency with which "sale" operations are used (typically less than 5\% of the time), we have omitted those operations from Table 2 to simplify the exposition. The results with the sale operations are supportive of the same conclusions that are supported with the purchase data but typically involve far fewer observations, are therefore more unreliable, and in some instances we were unable to estimate the model due to an insufficient number of observations.
} 
Before we comment on the results, it is worth discussing some elements of the estimation. First, the coefficients associated with the variable SURPRISE are difficult to estimate for three reasons: (i) there are only 115 target changes in total relative the 4,251 daily observations, (ii) the Desk seems to have shifted its preferences somewhat over the type of operation it uses to support a target change, variation in the reserve need, or accommodation of expectations of a target change, and (iii) some operations are rather infrequent (such as most "sale" operations), meaning that most of the days in the sample, these observations take the value zero. Despite these shortcomings, the "purchase" data $(O B, T B, P B)$ contain a sufficient number of non-zero observations, thus allowing for reasonable coefficient estimates. The estimates from the "sale" data (OS, TS, PS) confirm the findings with the "purchase" data in the sense that the coefficient estimates typically have the opposite sign of those in the "purchase" equations.

The estimates for the first sample (from April 25, 1984 to February 3, 1994) of "purchase" operations are representative of the canonical model of the federal funds market. Although outright transactions are more frequent (32\% of the time), these do not appear to be linked to fluctuations in the reserve need. This finding substantiates the claim that permanent operations are mostly used for technical reasons. By contrast, overnight operations (OB), although less frequent (10\% of the time), clearly respond to variations in the need in the direction of accommodating imbalances in the deviation of the federal funds rate from target. There appears to be little response to market expectations of a target change except for the first Friday in the maintenance period. The behavior of the SURPRISE variable is entirely consistent with a conventional liquidity effect: in order to drive the federal funds rate to its new, targeted level, the Fed injects/drains liquidity as needed. In fact, although the lag 1, and lag 3 coefficients are not statistically significant, all the coefficients have a negative sign, further substantiating this claim.

The dynamic correlations displayed in Table 3 suggest a fair amount of smoothing in the manner operations occur. Purchase operations appear to be complementary of each other in much the same way that sale operations are (the signs of the boxes along the diagonal are positive and significant). By contrast, purchase and sale operations are 
typically substitutes of one another (the signs of the boxes in the off-diagonal terms are usually negative and significant).

What is the effect of the new policy of announcing the target? First, the portfolio of operations shifts from permanent operations toward more temporary operations. In particular, while permanent operations (PB) where used $32 \%$ of the time in the 19841994 sub-sample, they were only used $11 \%$ and then $17 \%$ of the time over the 1994-1998 and 1998-2000 sub-samples respectively. Conversely, overnight operations (OB), which took place $10 \%$ of the time in the 1984-1994 sub-sample, are executed $27 \%$ and then $58 \%$ of the time during the 1994-1998 and 1998-2000 sub-samples respectively, a significant change.

Next, consider the evidence reported in the two rightmost blocks in Table 2. The pattern of responses to variations in the reserve need is similar to that in the first subsample. However, the response to expectations of a target change is somewhat mixed in the 1994-1998 sub-sample (OB operations are negative and significant on Thursdays, although TB operations are significant and positive on the first day of the maintenance period) but becomes noticeably more accommodating by the last sub-sample, typically in the form of TB operations early in the maintenance period. The pattern of coefficients for the SURPRISE variable seems to validate our notion that the Fed does not require open market operations to signal a new level for the federal funds rate. In the 1994-1998 sub-sample, the lag 0 coefficient is positive and marginally significant, suggestive of accommodation rather than enforcement. The lag 1 coefficient is negative and marginally significant which suggests that to some degree, open market operations were required to achieve the new targeted level of the federal funds rate, once it was announced.

These results confirm some of the hypotheses advanced in the previous sections and can be summarized as follows:

1. The announcement effect appears to be confirmed by the data, particularly for the 1998-2000 sub-sample. However, caution is advised since the last two subsamples contain a smaller number of target changes (20 between them) relative to the 1984-1994 sub-sample, which contained 95 changes. 
2. Expectations of a target change appear to be somewhat reinforced in the second sub-sample but mostly accommodated in the third sub-sample. In either case, the Fed's reaction appears to be circumscribed to the first days of the maintenance period.

3. The evidence is strongly suggestive that open market operations were used to enforce changes in the target during the first sub-sample, in a manner that is broadly consistent with the traditional liquidity effect.

4. Deviations of the federal funds rate from target are most persistent in the first subsample, which is consistent with the persistence observed in the size of each operation and would suggest that the Fed required more pressure in the federal funds market to guide the federal funds accordingly. The degree of persistence in operations decreases in the second sub-sample and almost completely disappears in the third sub-sample. However, the persistence of federal funds rate deviations from target is lower for the second and third sub-samples, suggesting that the Fed could exercise better control with less operations (see Figure 2).

\section{The Response of Term Rates}

The previous section investigated the behavior of the federal funds market in response to the Fed's practice of announcing changes in the federal funds rate (almost exclusively) after each FOMC meeting. We argued above that by providing a more regimented schedule in which to expect changes in the target, the Fed effectively signals its intentions and thus requires a smaller volume of open market operations. The questions we investigate in this section are tightly related to this scheduled-signaling mechanism. In particular, we explore the manner in which the scheduling of FOMC meetings coordinates the formation of expectations and the price discovery process of term rates. The results that we report below borrow heavily from Kuttner (2000).

It is important to begin by dissecting changes in the target into an expectational and a surprise component on account that it is the second of these components that will ultimately affect term rates in a rational expectations environment. Market expectations of changes in the target can be directly computed with data from the federal funds futures 
market. Specifically, Kuttner (2000) suggests that the surprise component of a target change can be constructed as,

$$
\widetilde{\varepsilon}_{\tau}=\frac{m_{s}}{m_{s}-\tau}\left(f_{s, \tau}^{0}-f_{s, \tau-1}^{0}\right)
$$

for all but the first and last days of the month. $\widetilde{\varepsilon}_{\tau}$ denotes the surprise component of a target change, $m_{s}$ denotes the number of days in month $s, \tau$ is the day of the month in which the target is changed and $f_{s, \tau}^{0}$ denotes the spot-month futures rate at date $\tau$ of month $s$ over which the average effective, overnight funds rate is computed to price the contract. The expected component of a target change can then be calculated as ${ }^{16}$

$$
E_{\tau-1}\left(\Delta f_{\tau}^{*}\right)=\Delta f_{\tau}^{*}-\widetilde{\varepsilon}_{\tau}
$$

were all the variables have been defined above and were we note that $\widetilde{\varepsilon}_{\tau}=-E_{\tau-1}\left(\Delta f_{\tau}^{*}\right)$ whenever $\Delta f_{\tau}^{*}=0$.

A broad interpretation of the rational expectations hypothesis would suggest that current term rates already incorporate expectations of future changes in the federal funds rate. Therefore, while at time $t$ the forecast $E_{t}\left(\Delta f_{t+1}{ }^{*}\right)$ is likely to be an important explanatory factor, at time $t+1$ only the forecast error $\tilde{\varepsilon}_{t+1}$ should have any significant effect on term rates. More specifically, let $\Delta R_{t}$ denote a generic term rate, then a simple regression such as,

$$
\Delta R_{t}=\alpha+\beta E_{t}\left(\Delta f_{t+1}^{*}\right)+u_{t}
$$

or

$$
\Delta R_{t+1}=\alpha+\beta \widetilde{\varepsilon}_{t+1}+v_{t+1}
$$

\footnotetext{
${ }^{16}$ For a detailed discussion of Kuttner's (2000) methodology, the reader is directed to consult the original reference.
} 
would likely present a non-zero, significant $\beta$ coefficient. However, how does the FOMC schedule and the expectation that changes in the federal funds rate target are almost exclusively announced after FOMC meetings modify the predictions embodied in equations (10) and (11)?

We argue that although expectations derived from the futures market from federal funds detect upcoming fluctuations in the federal funds rate, unless these fluctuations are associated with FOMC dates, they more likely represent technical and transitory deviations of the federal funds rate from target rather than a new level for the target itself. Consequently, outside FOMC dates, these futures-market based expectations are unlikely to have any significant effect on term rates.

To test this hypothesis, we use daily data on the repo (RP), the three-month T-Bill (TB3), and the ten-year T-Bond (TB10) rates over the period May 18, 1989 to August 14, $2000 .{ }^{17}$ In particular, consider estimating equation (10) but where the sample is restricted to meet the following three criteria:

- $\left|E_{t}\left(\Delta f_{t+1}{ }^{*}\right)\right|>0.125$, that is, to eliminate noisy fluctuations in the futures market, we limit the sample to dates in which expectations of a change in the federal funds rate amounted to at least $0.125 \%$ in absolute value.

- $d_{t}^{F O M C}=0$ (where $d_{t}^{F O M C}=1$ if there is an FOMC meeting in day $t, 0$ otherwise), i.e., we exclude FOMC dates.

- $d_{t}^{C H A N G E}=0$ (where $d_{t}^{C H A N G E}=1$ if the target is changed in date $t, 0$ otherwise), i.e., we exclude dates when the target was changed.

Imposing these restrictions reduces the sample to 184 observations. Table 6 reports the results of this experiment for $\Delta R_{t}=\mathrm{RP}, \mathrm{TB} 3$, and TB10. As is clear from Table 6, there is virtually no response of term rates to expectations of changes in the federal funds rate outside FOMC dates or dates when the target is changed. The explained variation in all cases remains below $4 \%$ and although the coefficients are technically statistically significant, they are clearly indistinguishable from 0 by any reasonable economic metric. The results are virtually identical when the restriction $\left|E_{t}\left(\Delta f_{t+1}{ }^{*}\right)\right|>0.125$ is eliminated, allowing the sample to expand to 2817 observations.

\footnotetext{
${ }^{17}$ May 18, 1989 is the earliest date for which we have reliable data on the federal funds futures market which was established in 1988.
} 
A natural complement to the previous experiment is to concentrate on dates in which the target was in fact changed and proceed on to ask whether or not changes in the target executed outside FOMC meetings were more influential. Under the view that the FOMC schedule regiments expectations on when are target changes most likely to occur, a target change announced outside an FOMC meeting constitutes a rather unusual event (such observation is born out by the data, as we discussed above). Additionally, we are interested in examining what Kuttner (2000) labels as "the timing hypothesis," that is, whether the mere advancement or postponement of anticipated rate changes will have a smaller effect on term rates than actions that truly signify a directional change in the policy stance. In essence, this means that the forecast error $\tilde{\varepsilon}_{t}$ may, at times, represent having gotten the timing of a target change incorrectly although that target change may have been widely expected to occur sometime in the near future.

A simple way to explore both of these issues simultaneously is to estimate a regression on a sample that only contains dates of a target change, similar in spirit to Cook and Hahn (1989), and Kuttner's (2000) equation (8). Consider the dummy variable $d_{\tau}^{\text {FOMC }}$ which is described above and then define an additional dummy variable, $d_{\tau}^{\text {SWITCH }}$ which takes the value of 1 if the $\tau^{\text {th }}$ target change has the opposite sign of the $\tau$ - 1 target change and is 0 otherwise. The choice of this variable definition is based on the observation, reported among other places in Rudebusch (1995), that the Fed typically changes the target in the same direction but only infrequently chooses to move the target in the opposite direction. Thus, the variable $d_{\tau}^{\text {SWITCH }}$ will help us identify the importance of the timing hypothesis, albeit admittedly, in a crude way. With these considerations in mind, the regression we estimate is

$$
\begin{aligned}
& \Delta R_{\tau}=\alpha_{0}+\alpha_{f} d_{\tau}^{\text {FOMC }}+\alpha_{s} d_{\tau}^{\text {SWITCH }}+\beta_{1}^{0} E_{\tau-1}\left(\Delta f_{\tau}^{*}\right)+\beta_{1}^{f} d_{\tau}^{\text {FOMC }} E_{\tau-1}\left(\Delta f_{\tau}^{*}\right)+ \\
& \beta_{1}^{s} d_{\tau}^{\text {SWITCH }} E_{\tau-1}\left(\Delta f_{\tau}^{*}\right) d_{\tau}^{\text {SWITCH }}+\beta_{2}^{0} \tilde{\varepsilon}_{\tau}+\beta_{2}^{f} d_{\tau}^{F O M C} \widetilde{\varepsilon}_{\tau}+\beta_{2}^{s} d_{\tau}^{\text {SWITCH }} \tilde{\mathcal{\varepsilon}}_{\tau}+u_{\tau}
\end{aligned}
$$

where $\Delta R_{\tau}=\mathrm{RP}, \mathrm{TB} 3$, and TB10. The results of this experiment are reported in Table 7. The discussion of the results centers on the $\beta_{2}{ }^{i}$ coefficients $(i=0, f, s)$, which are the coefficients associated with the prediction errors, and therefore, whose estimates should 
be close to the value of 1 . The $\beta_{1}{ }^{i}$ coefficients $(i=0, f, s)$ are those associated with the expectational component of target changes and should therefore be statistically irrelevant under the rational expectations hypothesis. Generally speaking, this is in fact what we find.

The parametrization of equation (12) measures the response of term rates to surprise changes in the target announced at an FOMC meeting as the coefficient sum $\hat{\beta}_{2}^{0}+\hat{\beta}_{2}^{f}$. This response takes on the values $0.20(0.86), 0.62(0.32)$ and $-0.23(0.32)$ for the repo, three-month T-Bill and ten-year T-Bond rates respectively (standard errors in parenthesis). These values are not particularly close to the canonical value of 1 (specially for the ten-year T-bond rate). However, if instead we consider the same response when the target change is announced outside and FOMC meeting (i.e., looking at $\hat{\beta}_{2}^{0}$ in isolation), notice that the values uniformly increase to $0.54(0.31), 0.73(0.11)$, and 0.44 (0.11) for RP, TB3, and TB10 respectively (standard errors in parenthesis). These values are closer to 1 and highlight the "specialness" of FOMC meeting days.

In addition to these results, equation (12) also allows us to investigate the validity of Kuttner's (2000) timing hypothesis. Thus, the response of term rates to surprise target changes that correspond to a shift in the direction of previous changes can be measured as the sum of the coefficients $\hat{\beta}_{2}^{0}+\hat{\beta}_{2}^{f}+\hat{\beta}_{2}^{s}$. For RP, TB3, and TB10, these coefficient estimates and their standard errors are respectively, 0.19 (1.47), 1.08 (0.55), and 1.48 (0.55), which strongly suggest (except for the repo rate) that the timing hypothesis is important. Finally, we consider the extreme case of a target change that corresponds to a shift in direction, which is made outside and FOMC meeting. This corresponds to the strongest signal that the Fed could send and can be measured by the coefficient sum $\hat{\beta}_{2}^{0}+\hat{\beta}_{2}^{s}$. The estimates of this type of response for RP, TB3, and TB10 (standard errors in parenthesis) are $0.52(1.73), 1.19(0.64)$, and 2.15 (0.65), respectively.

Overall, these results are consistent with the rational expectations hypothesis and the view that the FOMC schedule imposes a specific timetable on which to expect decisions that will affect the level of the federal funds rate target. As the maturity of the term rate considered increases, we find that the response to unusual events (such as a target change announced outside and FOMC meeting that constitutes a reversal in the 
direction of previous changes) also becomes stronger. The timing hypothesis advanced by Kuttner (2000) appears to be well supported by the data. By contrast, the response to target changes that take place at FOMC meetings is weaker as long as these changes follow the same general direction of previous changes.

\section{Conclusions}

After having maintained the federal funds rate unchanged since September 4, 1992, the February 3-4, 1994 FOMC meeting concluded with the decision to modify the federal funds rate target, and to ensure that this policy decision was properly communicated to the markets, it was disclosed by way of a public announcement. Thus, what began as an experiment has now become part of the Fed's tradition, a tradition that is now shared by numerous central banks. One of the practical implications of this policy consists of the ability to control the federal funds rate with little or no immediate action by the Trading Desk - the announcement effect. The market's understanding and expectation of how the Fed operates has also molded the behavior of market rates at different maturities.

The daily conduct of open market operations is a complex process: it is influenced by a large variety of technical factors that are often unrelated to monetary policy per se. In addition, a number of procedural changes have characterized the reserves market and the manner the Desk manages the reserve need. These difficulties notwithstanding, the analysis based on the pattern and choice of open market operations confirms the notion that the Desk is able to communicate a new level for the federal funds rate with a smaller volume of interventions than was characteristic prior to 1994. Traders are placing increased credibility in the Desk's commitment to maintain the federal funds rate on target, a notion that is cemented by the clarity that the regular announcement of FOMC outcomes provides.

Ultimately, the goals of monetary policy require that the Fed be successful in guiding the market's expectations of future policy moves and thus, that there be some synchronicity in longer maturity rate movements. The evidence we provide on this front is consistent with the view that expectations are updated with the FOMC calendar. Long- 
term rates appear to react strongly when the Fed initiates policy moves in a new direction in a manner consistent with the timing hypothesis, but remain quiescent subsequently. Shorter-term rates track the Fed's policy moves more closely, as one would expect from their maturity, but react less strongly to unusual events.

\section{References}

Akhtar, M.A. (1997), Understanding Open Market Operations, Public Information Department, Federal Reserve Bank of New York.

Anderson, R. G. and Raasche, R. H. (2000), "Retail Sweep Programs and Bank Reserves, 1994-1999," Federal Reserve Bank of St. Louis, working paper 2000-023A.

Bartolini, L., Bertola, G. and Prati, A. (2000), "Day-to-Day Monetary Policy and the Volatility of the Federal Funds Interest Rate," Federal Reserve Bank of New York, Staff Report no. 110.

Clouse, J. A. and Dow, J. P. (2000), “A Computational Model of Banks' Optimal Reserve Management Policy," Federal Reserve Board, manuscript.

Cohen, G. D. (1996), “Open Market Operations during 1996,” Federal Reserve Bulletin, July 1997.

Demiralp S., and Jordá O. (2000), “The Pavlovian Response of Term Rates to Fed Announcements," Federal Reserve Board Working papers, Finance and Economics Discussion Series, 2001-10.

Edwards C. L. (1997), “Open Market Operations in 1990s," Federal Reserve Bulletin, November 1997.

Feinman J. (1993), "Estimating the Open Market Desk's Daily Reaction Function," Journal of Money, Credit, and Banking, Vol. 25, No 2.

Furfine, C. H. (2000), “Interbank Payments and the Daily Federal Funds Rate," Journal of Monetary Economics, 46, 535-553.

Gilbert, R A. (1985), “Operating Procedures for Conducting Monetary Policy,” Review, Federal Reserve Bank of St. Louis, February, 13-21.

Goodfriend M., and Whelpley W. (1993), "Federal Funds: Instrument of Federal Reserve Policy," in Timothy Q. Cook and Robert K.LaRoche, eds., Instruments of the Money Market. Richmond: Federal Reserve Bank of Richmond. 
Guthrie, G., and Wright, J. (2000), "Open Mouth Operations," Journal of Monetary Economics, 46, Issue 2, 489-516.

Hamilton, J. D. (1997), "Measuring the Liquidity Effect," American Economic Review, vol. 87 , no. $1,80-97$.

Hamilton J. D., and Jordá O. (2000), "A Model for the Federal Funds Rate Target," NBER working paper 7847.

Heller, H.R. (1987), "Implementing Monetary Policy," Federal Reserve Bulletin, July, 419-429.

Hilton, S. (1999), "Highlights of Domestic Open Market Operations during 1998," Federal Reserve Bulletin, April 1999.

Kuttner, KN. (2000), "Monetary Policy Surprises and Interest Rates: Evidence from the Fed Funds Futures Market," Journal of Monetary Economics, forthcoming

Lumpkin, S. (1993), "Repurchase and Reverse repurchase Agreements," in Timothy Q. Cook and Robert K LaRoche, eds., Instruments of the Money Market. Richmond: Federal Reserve Bank of Richmond.

Meulendyke, A M. (1998), U.S Monetary Policy and Financial Markets, Federal Reserve Bank of New York.

Maddala , GS. (1983), Limited-dependent and Qualitative Variables in Econometrics, Cambridge, New York: Cambridge University Press.

Orphanides, Athanasios (2001), Comments on: "Expectations, Open Market Operations, and Changes in the Federal Funds Rate," by John B. Taylor. Federal Reserve Bank of St. Louis, Review, forthcoming.

Rudebusch, Glenn D. (1995), "Federal Reserve Interest Rate Targeting, Rational Expectations and the Term Structure," Journal of Monetary Economics, 35, 245-274. Erratum: December 1995.

Taylor, J B. (2001), "Expectations, Open Market Operations, and Changes in the Federal Funds Rate," Federal Reserve Bank of St. Louis, Review, forthcoming.

Thornton, DL. (2001), “ The Market Reaction to Changes in he Fed's Fund Rate Target: Has the Fed Used Open Mouth Operations?" Federal Reserve Bank of St. Louis, Review, forthcoming.

Woodford, M. (2000), "Monetary Policy in a World without Money," International Finance, Vol. 3, n. 2, 229-260. 


\section{Appendix}

\section{A.1 Open Market Operations}

The Trading Desk of the Federal Reserve Bank of New York implements open market operations. There are two types of operations depending on the duration of the operation. If the reserve need or surplus is expected to be persistent, then the desk may conduct permanent operations through outright purchases or sales of securities. Outright purchases or sales of Treasury debt (i.e. Treasury Bills or Treasury Coupon securities) are permanent operations that are generally executed in the market at times when the estimated need or surplus is expected to be large and is expected to extend a few periods into the future (these variations in the need are mostly associated with increases in the demand for currency). Typically, the Desk does not address small reserve shortages or excesses of brief duration with outright operations, which entail greater execution costs and can be affected by market price changes.

Alternatively, if staff projections indicate a short-lived need to add or drain reserves, the Desk undertakes temporary operations. Temporary operations are repurchase agreements (RPs) or matched sale purchase (MSP) transactions. Note that a purchase adds to reserves whereas a sale drains reserves from the banking system. In managing bank reserves, the Manager (of the Trading Desk) finds it helpful to put reserves in or take them out in large volume for one day to a few days at a time. RPs and MSPs are temporary transactions that enable the Desk to respond quickly when reserves fall short of desired levels or prove to be in excess. Temporary operations are particularly helpful in dealing with the uncertainties present in the reserves market (see Meulendyke, 1998, chapter 7).

According to Feinman (1993), in the pre-1994 regime the Federal Reserve signals the strongest protest of a policy easing with overnight RP transactions. Meanwhile, term RPs contain a much weaker rate protest. Edwards (1997) notes that term repurchase agreements were considered more technical and do not aim to signal target changes. Term RPs are usually designed to leave reserve shortages of moderate size to be addressed with additional RPs (Hilton, 1999). 
It is important to note that there has been an increasing tendency over the last decade for the Desk to be in a position of needing to add reserves (see the discussion below). This is because the Desk does not want to drain reserves during periods where low operating balances might lead to late day firmness in the money market (see Cohen, 1996), and also because of the Desk's response to an increasing demand for currency over time. Consequently, because the portfolio has been expanding in recent years, MSPs have been used less frequently than RPs (see Meulendyke, 1998, chapter 7).

\section{A.2 The Autoregressive Conditional Hazard Model (ACH)}

The methodology described in this section is explained in detail in Hamilton and Jordá (2000) and Demiralp and Jordá (2000). For brevity, we describe only the salient features. Details about the estimates and the forecasts themselves are available from the authors upon request.

The ACH model seeks an answer to the following question: What is the probability that during the next maintenance period, the target will be changed, conditional on information available today? Denote with $x_{t}=1$ if the target is changed during the maintenance period $t$ and $x_{t}=0$ otherwise. Then, the conditional probability of a target change is a discrete-time hazard that can be modeled as the following $\mathrm{ACH}(\mathrm{p}, \mathrm{q})$,

$$
\begin{aligned}
& P\left(x_{t}=1 \mid \Omega_{t}\right)=h_{t}=\left[1+\exp \left(\lambda_{t}\right)\right]^{-1} \\
& \lambda_{t}=\omega+\sum_{j=1}^{p} \theta_{j} u_{w_{j}(t-1)}+\sum_{j=1}^{q} \beta_{j} \lambda_{w_{j}(t-1)}+\delta^{\prime} z_{t-1}
\end{aligned}
$$

where $\omega$ is a constant term, $w_{j}(t-1)$ is an index that records the $j^{\text {th }}$ most recent target change as of time (t-1), $u_{w_{j}(t-1)}$ therefore denotes the duration between the $j^{\text {th }}$ two most recent target changes as of date $t-1$ and $z_{t-1}$ is a vector of exogenous variables. The specification in (A.1) is dynamic in a manner similar to conventional ARMA and ARCH models and ensured that the probability $h_{t}$ is between 0 and 1 . The likelihood associated with (A.1) is 


$$
L(\Pi)=\sum_{t=1}^{T}\left\{x_{t} \log \left(h_{t}\right)+\left(1-x_{t}\right) \log \left(1-h_{t}\right)\right\}
$$

which can be maximized by conventional numerical techniques.

\section{Forecasting target changes with the ACH}

The ACH produces forecasts of when the target will be changed next, which can be easily combined with forecasts of the expected magnitude of the target change when it occurs. Due to the discrete nature of target changes, which typically come in increments of 25 basis points, we model this process with an ordered response model with normal errors (ordered probit model, or OP for short). The ACH and the OP are then estimated over two samples at a maintenance-period frequency: April 25, 1984 to February 2, 1994 and February 16, 1994 to August 23, 2000. The first sample was modeled with an $\operatorname{ACH}(1,1)$ that included as exogenous variables, whether the FOMC met during the current and previous maintenance period or not, and the most recently available information on CPI inflation. The corresponding OP contained as regressors the size of the previous target change, the spread between the target and the one-year T-bond, the spread between the target and the discount rate, and the ratio of nonborrowed reserves to lagged total reserves. The second sample required an $\mathrm{ACH}(1,1)$ that included the same FOMC variable from the first sample, the absolute value of the spread between the ten-year Tbond and the federal funds rate, and the duration since the last change in the prime rate. The companion OP model included as regressors, the value of the most recent target change, the spread between the six-month T-Bill and the ten-year T-bond and the spread between the target and the prime rate. 
Table 1 - Types of Open Market Operation

\begin{tabular}{|c|c|c|c|c|}
\hline & $\begin{array}{l}\text { Adds Liquidity } \\
\text { (Purchases) }\end{array}$ & Acronym & $\begin{array}{c}\text { Drains Liquidity } \\
\text { (Sales) }\end{array}$ & Acronym \\
\hline $\begin{array}{l}\text { Permanent } \\
\text { (Outright) }\end{array}$ & $\begin{array}{l}\text { T-Bill domestic purchases } \\
\text { T- Bill foreign purchases } \\
\text { Coupon domestic purchases } \\
\text { Coupon foreign purchases }\end{array}$ & PB & $\begin{array}{l}\text { T-Bill Sales } \\
\text { Coupon Sales }\end{array}$ & PS \\
\hline Temporary & Term RP purchases & TB & $\begin{array}{c}\text { Term Matched Sale } \\
\text { Purchases }\end{array}$ & TS \\
\hline Overnight & Overnight RP Purchases & OB & $\begin{array}{c}\text { Overnight Matched Sale } \\
\text { Purchases }\end{array}$ & OS \\
\hline
\end{tabular}


Table 2 - Signs of the Coefficients in the TOBIT Regressions: Purchase Operations

\begin{tabular}{|c|c|c|c|c|c|c|c|c|c|c|c|c|c|c|c|c|c|c|}
\hline \multirow[b]{3}{*}{ Day } & \multicolumn{6}{|c|}{ 1984-1994 } & \multicolumn{6}{|c|}{ 1994-1998 } & \multicolumn{6}{|c|}{ 1998-2000 } \\
\hline & \multicolumn{3}{|c|}{ Need } & \multicolumn{3}{|c|}{ Expected } & \multicolumn{3}{|c|}{ Need } & \multicolumn{3}{|c|}{ Expected } & \multicolumn{3}{|c|}{ Need } & \multicolumn{3}{|c|}{ Expected } \\
\hline & $\overline{\mathrm{OB}}$ & TB & PB & $\overline{\overline{O B B}}$ & $\bar{T}$ TB & PB & $\overline{\mathrm{OB}}$ & TB & PB & $\overline{\mathrm{OB}}$ & TB & PB & $\overline{\mathrm{OB}}$ & TB & $\overline{\mathbf{P B}}$ & $\overline{\mathrm{OB}}$ & $\bar{T}$ TB & PB \\
\hline $\begin{array}{l}\text { Thursday } \\
1\end{array}$ & + & . & . & $\cdot$ & . & $\cdot$ & . & ++ & . & -- & ++ & . & $\cdot$ & . & . & . & ++ & . \\
\hline $\begin{array}{l}\text { Friday } \\
2\end{array}$ & ++ & . & . & . & ++ & . & ++ & . & . & . & . & . & -- & . & . & ++ & ++ & . \\
\hline $\begin{array}{l}\text { Monday } \\
\mathbf{3}\end{array}$ & + & . & . & . & . & . & . & . & $\cdot$ & $\cdot$ & . & . & . & + & . & . & . & . \\
\hline $\begin{array}{l}\text { Tuesday } \\
\mathbf{4}\end{array}$ & ++ & . & . & . & . & . & + & - & . & . & . & + & . & . & . & . & . & . \\
\hline $\begin{array}{l}\text { Wednes. } \\
\mathbf{5}\end{array}$ & . & ++ & . & . & . & . & ++ & . & . & -- & . & . & . & . & & . & . & - \\
\hline $\begin{array}{l}\text { Thursday } \\
6\end{array}$ & ++ & . & . & $\cdot$ & . & . & . & . & . & - & . & + & . & . & . & . & . & . \\
\hline $\begin{array}{l}\text { Friday } \\
7\end{array}$ & ++ & . & . & . & . & . & . & . & . & . & . & . & ++ & . & . & . & . & . \\
\hline $\begin{array}{l}\text { Monday } \\
8\end{array}$ & + & . & . & . & . & . & . & . & . & . & . & . & + & . & . & - & $\cdot$ & . \\
\hline $\begin{array}{l}\text { Tuesday } \\
9\end{array}$ & ++ & . & . & . & . & . & . & . & . & . & . & . & + & . & . & . & $\cdot$ & . \\
\hline $\begin{array}{l}\text { Wednes. } \\
10\end{array}$ & + & & . & $\cdot$ & . & . & . & . & . & . & . & . & . & . & . & . & . & . \\
\hline
\end{tabular}

\section{Surprise - Lag}

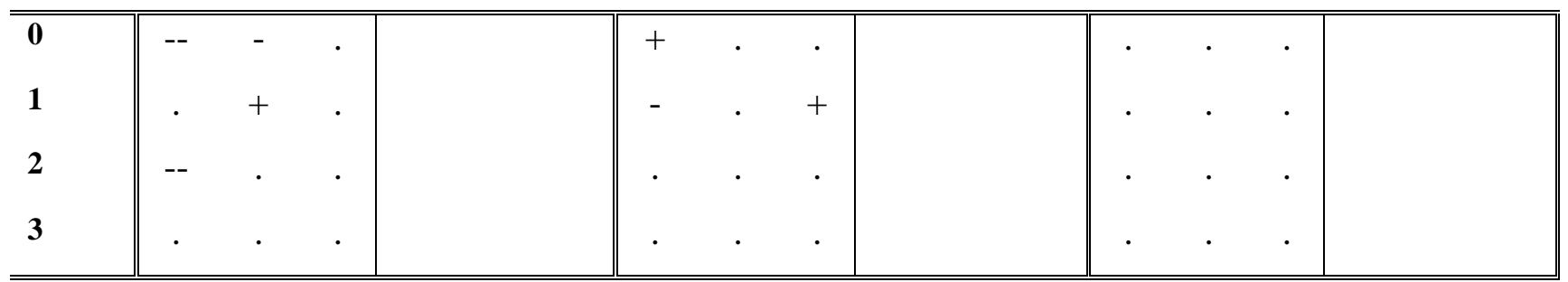

Note: ++/-- indicates a positive/negative coefficient significant at the $95 \%$ confidence level. +/- indicated a positive/negative coefficient significant at the $90 \%$ confidence level. ".” Indicates a coefficient that is not statistically significant. $\mathrm{OB}=$ overnight purchase operations; $\mathrm{TB}=$ temporary purchase operations; and $\mathrm{PB}$ $=$ outright (permanent) purchase operations. 
Table 3 - Signs of the Lagged Coefficients of the Open Market Data in the TOBIT Regressions by Sub Sample

Sample 1 - 1984-1994

\begin{tabular}{|c|c|c|c|c|c|c|c|c|c|c|c|c|c|c|c|c|c|c|}
\hline & \multicolumn{6}{|c|}{ Lag 1} & \multicolumn{6}{|c|}{ Lag 2} & \multicolumn{6}{|c|}{ Lag 3} \\
\hline & OB & TB & PB & OS & TS & PS & OB & TB & PB & OS & TS & PS & OB & TB & PB & OS & TS & PS \\
\hline OB & ++ & ++ & . & - & . & . & + & . & . & . & . & . & . & + & . & . & . & - \\
\hline TB & ++ & + & ++ & -- & . & . & -- & ++ & . & . & . & . & . & ++ & . & . & . & - \\
\hline PB & . & + & ++ & - & -- & . & . & ++ & ++ & -- & -- & . & . & . & ++ & -- & -- & . \\
\hline OS & . & -- & -- & ++ & ++ & ++ & . & - & . & . & . & . & . & - & . & . & . & . \\
\hline TS & . & . & . & . & ++ & . & . & . & . & . & ++ & . & . & . & . & . & ++ & . \\
\hline PS & . & . & . & . & . & . & . & . & . & . & . & . & . & . & . & . & . & . \\
\hline
\end{tabular}

Sample 2 - 1994-1998

Lag $1 \quad$ Lag 2 Lag 3

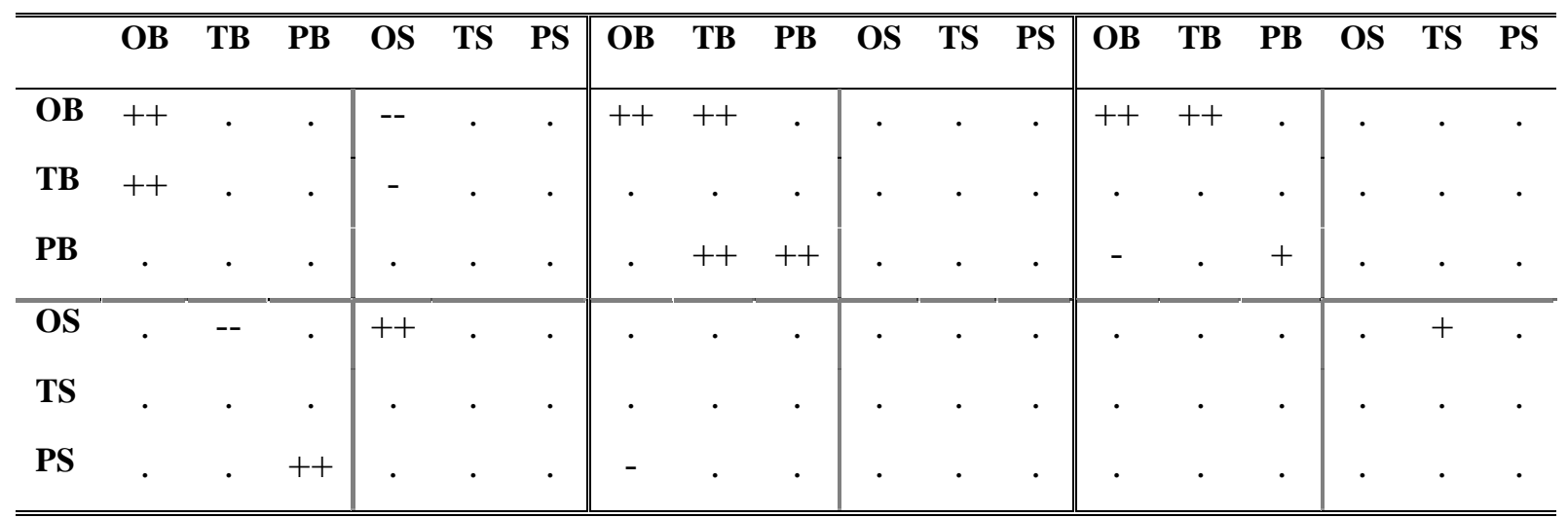

Sample 3-1998-2000

Lag 1

Lag 2

Lag 3

\begin{tabular}{ccccccc|ccccccc|cccccc}
\hline \hline & OB & TB & PB & OS & TS & PS & OB & TB & PB & OS & TS & PS & OB & TB & PB & OS & TS & PS \\
\hline OB & $\cdot$ & $\cdot$ & - & - & $\cdot$ & ++ & $\cdot$ & $\cdot$ & $\cdot$ & $\cdot$ & $\cdot$ & $\cdot$ & $\cdot$ & $\cdot$ & - & $\cdot$ & $\cdot$ & $\cdot$ \\
TB & $\cdot$ & $\cdot$ & $\cdot$ & $\cdot$ & $\cdot$ & $\cdot$ & $\cdot$ & $\cdot$ & $\cdot$ & $\cdot$ & $\cdot$ & $\cdot$ & - & $\cdot$ & $\cdot$ & - & $\cdot$ & $\cdot$ \\
PB & $\cdot$ & $\cdot$ & $\cdot$ & $\cdot$ & $\cdot$ & $\cdot$ & $\cdot$ & $\cdot$ & ++ & $\cdot$ & $\cdot$ & $\cdot$ & $\cdot$ & $\cdot$ & + & $\cdot$ & $\cdot$ & + \\
\hline OS & - & - & $\cdot$ & $\cdot$ & $\cdot$ & $\cdot$ & $\cdot$ & $\cdot$ & $\cdot$ & $\cdot$ & $\cdot$ & $\cdot$ & $\cdot$ & - & $\cdot$ & $\cdot$ & + & $\cdot$ \\
TS & $\cdot$ & $\cdot$ & $\cdot$ & $\cdot$ & $\cdot$ & $\cdot$ & $\cdot$ & $\cdot$ & $\cdot$ & $\cdot$ & $\cdot$ & $\cdot$ & $\cdot$ & $\cdot$ & $\cdot$ & $\cdot$ & $\cdot$ & $\cdot$ \\
PS & $\cdot$ & $\cdot$ & $\cdot$ & $\cdot$ & $\cdot$ & $\cdot$ & $\cdot$ & $\cdot$ & $\cdot$ & ++ & $\cdot$ & + & $\cdot$ & ++ & $\cdot$ & $\cdot$ & $\cdot$ & $\cdot$ \\
\hline
\end{tabular}

Note: ++/-- indicates a positive/negative coefficient significant at the $95 \%$ confidence level. + /- indicated a positive/negative coefficient significant at the $90 \%$ confidence level. "." Indicates a coefficient that is not statistically significant. $\mathrm{OB}=$ overnight purchase operations; $\mathrm{TB}=$ temporary purchase operations; and $\mathrm{PB}$ $=$ outright (permanent) purchase operations. $\mathrm{OS}=$ overnight sale operations; $\mathrm{TS}=$ temporary sale operations; and PS = outright (permanent) sale operations. 
Table 4 - TOBIT Regressions for the Open Market Purchase Data

$$
\begin{gathered}
x_{k t}^{*}=\alpha_{t}+\pi^{\prime} \mathbf{z}_{t}+\gamma_{t}^{N} \operatorname{NEED}_{t-1}+\gamma_{t}^{E} \text { EXPECT }_{t-1}+ \\
\gamma_{0}^{S} \text { SURPRISE }_{t}+\gamma_{1}^{S} S U R P R I S E_{t-1}+\gamma_{2}^{S} S U R P R I S E_{t-2}+\gamma_{3}^{S} S U R P R I S E_{t-3}+\varepsilon_{k t}
\end{gathered}
$$

\section{Coefficient estimates for the SURPRISE regressors}

\begin{tabular}{|c|c|c|c|c|c|c|c|c|c|}
\hline & \multicolumn{3}{|c|}{ OB } & \multicolumn{3}{|c|}{ TB } & \multicolumn{3}{|c|}{ PB } \\
\hline & 1984-1994 & 1994-1998 & 1998-2000 & 1984-1994 & 1994-1998 & 1998-2000 & 1984-1994 & 1994-1998 & 1998-2000 \\
\hline Lag 0 & & & & & & & & & \\
\hline$\gamma_{0}{ }^{S}$ & $\begin{array}{c}-28.58^{* *} \\
(11.43)\end{array}$ & $\begin{array}{l}15.24 * \\
(8.75)\end{array}$ & $\begin{array}{c}1.94 \\
(11.51)\end{array}$ & $\begin{array}{l}-53.66^{*} \\
(29.53)\end{array}$ & $\begin{array}{c}21.15 \\
(68.18)\end{array}$ & $\begin{array}{c}-2.86 \\
(116.51)\end{array}$ & $\begin{array}{l}-14.40 \\
(9.26)\end{array}$ & $\begin{array}{c}30.69 \\
(33.98)\end{array}$ & $\begin{array}{c}7.73 \\
(47.59)\end{array}$ \\
\hline $\begin{array}{l}\text { Lag } 1 \\
\gamma_{1}^{S}\end{array}$ & $\begin{array}{c}-2.80 \\
(14.70)\end{array}$ & $\begin{array}{l}-21.42 * \\
(11.66)\end{array}$ & $\begin{array}{c}-8.03 \\
(11.88)\end{array}$ & $\begin{array}{l}72.78 * \\
(38.42)\end{array}$ & $\begin{array}{c}27.17 \\
(50.74)\end{array}$ & $\begin{array}{l}-126.67 \\
(131.86)\end{array}$ & $\begin{array}{c}15.20 \\
(10.83)\end{array}$ & $\begin{array}{l}66.78^{*} \\
(39.02)\end{array}$ & $\begin{array}{l}-19.06 \\
(54.39)\end{array}$ \\
\hline $\begin{array}{l}\text { Lag } 2 \\
\gamma_{2}^{S}\end{array}$ & $\begin{array}{c}-42.29 * * \\
(14.56)\end{array}$ & $\begin{array}{l}-18.47 \\
(17.64)\end{array}$ & $\begin{array}{c}-7.51 \\
(13.39)\end{array}$ & $\begin{array}{c}5.28 \\
(35.11)\end{array}$ & $\begin{array}{l}-56.71 \\
(59.00)\end{array}$ & $\begin{array}{c}-93.72 \\
(79.92)\end{array}$ & $\begin{array}{c}2.13 \\
(11.02)\end{array}$ & $\begin{array}{c}42.45 \\
(38.61)\end{array}$ & $\begin{array}{c}4.11 \\
(38.59)\end{array}$ \\
\hline $\begin{array}{l}\text { Lag } 3 \\
\gamma_{3}{ }^{S}\end{array}$ & $\begin{array}{l}-19.09 \\
(12.96)\end{array}$ & $\begin{array}{c}-24.12 \\
(18.61)\end{array}$ & $\begin{array}{c}-8.50 \\
(13.44)\end{array}$ & $\begin{array}{l}-12.63 \\
(40.45)\end{array}$ & $\begin{array}{l}-29.72 \\
(87.75)\end{array}$ & $\begin{array}{l}-167.15 \\
(114.22)\end{array}$ & $\begin{array}{l}-6.00 \\
(10.37)\end{array}$ & $\begin{array}{c}49.76 \\
(38.08)\end{array}$ & $\begin{array}{c}0.20 \\
(53.99)\end{array}$ \\
\hline Frequency & $10.04 \%$ & $26.50 \%$ & $58.16 \%$ & $13.06 \%$ & $24.89 \%$ & $32.44 \%$ & $31.91 \%$ & $11.18 \%$ & $16.51 \%$ \\
\hline
\end{tabular}

\section{Dependent Variables}

Notes: Equation (6) is estimated for each type of purchase operation. The coefficient estimates in this table correspond to the bottom part of Table 2. Frequency refers to the proportion of days in the sample the operation was used. $* *(*)$ indicates significant at the $95 \%(90 \%)$ confidence level. OB = overnight purchase operations; $\mathrm{TB}=$ temporary purchase operations; and $\mathrm{PB}=$ outright (permanent) purchase operations. 
Table 5 - TOBIT Regressions for the Open Market Sale Data

$$
\begin{gathered}
x_{k t}^{*}=\alpha_{t}+\pi^{\prime} \mathbf{z}_{t}+\gamma_{t}^{N} N E E D_{t-1}+\gamma_{t}^{E} \text { EXPECT }_{t-1}+ \\
\gamma_{0}^{S} \text { SURPRISE }_{t}+\gamma_{1}^{S} \text { SURPRISE }_{t-1}+\gamma_{2}^{S} \text { SURPRISE }_{t-2}+\gamma_{3}^{S} \text { SURPRISE }_{t-3}+\varepsilon_{k t}
\end{gathered}
$$

\section{Coefficient estimates for the SURPRISE regressors}

\begin{tabular}{|c|c|c|c|c|c|c|c|c|c|}
\hline & \multicolumn{3}{|c|}{ OS } & \multicolumn{3}{|c|}{ TS } & \multicolumn{3}{|c|}{ PS } \\
\hline & 1984-1994 & 1994-1998 & 1998-2000 & 1984-1994 & 1994-1998 & $1998-2000$ & 1984-1994 & 1994-1998 & $1998-2000$ \\
\hline Lag 0 & & & & & & & & & \\
\hline$\gamma_{0}^{S}$ & $\begin{array}{c}31.44 * * \\
(14.41)\end{array}$ & $\begin{array}{l}-25.02 \\
(52.34)\end{array}$ & $\begin{array}{c}27.44 \\
(75.33)\end{array}$ & $\begin{array}{c}-9.84 \\
(31.54)\end{array}$ & $\begin{array}{c}119.00 \\
(999.99)\end{array}$ & - & - & $\begin{array}{c}-8.07 \\
(73.76)\end{array}$ & $\begin{array}{c}517.66 \\
(999.99)\end{array}$ \\
\hline Lag 1 & & & & & & & & & \\
\hline$\gamma_{i}^{S}$ & $\begin{array}{c}10.86 \\
(10.51)\end{array}$ & $\begin{array}{c}7.74 \\
(141.49)\end{array}$ & $\begin{array}{c}9.40 \\
(37.14)\end{array}$ & $\begin{array}{c}-69.52^{* * *} \\
(31.88)\end{array}$ & $\begin{array}{c}-162.94 * \\
(85.35)\end{array}$ & - & - & $\begin{array}{l}-11.70 \\
(92.35)\end{array}$ & $\begin{array}{l}-130.07 \\
(171.78)\end{array}$ \\
\hline $\begin{array}{l}\text { Lag } 2 \\
\gamma_{2}^{S}\end{array}$ & $\begin{array}{c}3.15 \\
(10.22)\end{array}$ & $\begin{array}{c}4.05 \\
(21.55)\end{array}$ & $\begin{array}{c}0.89 \\
(25.86)\end{array}$ & $\begin{array}{l}-10.79 \\
(32.74)\end{array}$ & - & - & - & - & \\
\hline $\begin{array}{l}\text { Lag } 3 \\
\gamma_{3}^{S}\end{array}$ & $\begin{array}{c}0.31 \\
(9.79)\end{array}$ & $\begin{array}{c}-76.75^{* *} \\
(31.70)\end{array}$ & $\begin{array}{l}25.46^{*} \\
(15.14)\end{array}$ & $\begin{array}{c}57.13 \\
(47.46)\end{array}$ & - & - & - & - & \\
\hline Frequency & $5.33 \%$ & $4.33 \%$ & $4.80 \%$ & $3.22 \%$ & $1.44 \%$ & $0.00 \%$ & $0.00 \%$ & $1.69 \%$ & $2.96 \%$ \\
\hline
\end{tabular}

Dependent variables

Notes: Equation (6) is estimated for each type of sale operation. Frequency refers to the proportion of days in the sample the operation was used. **(*) indicates significant at the $95 \%(90 \%)$ confidence level. OS = overnight sale operations; TS = temporary sale operations; and PS = outright (permanent) sale operations. 
Table 6 - The Response of Term Rates to Expectations Outside FOMC days

$$
\Delta R_{t}=\alpha+\beta E_{t}\left(\Delta f_{t+1}^{*}\right)+u_{t}
$$

\begin{tabular}{cccc}
\hline \hline$\Delta R_{t}$ & Intercept $-\alpha$ & Response $-\beta$ & $\mathrm{R}^{2}$ \\
\hline Repo Rate & $0.03^{*}$ & $-0.04^{* *}$ & 0.04 \\
& $(0.01)$ & $(0.02)$ & \\
3-month T-Bill & 0.00 & $0.01^{* *}$ & 0.02 \\
& $(0.00)$ & $(0.00)$ & 0.04 \\
10-year T- Bond & 0.00 & $0.01^{* *}$ & \\
& $(0.01)$ & $(0.00)$ & \\
\hline \hline
\end{tabular}

Sample: May 18, 1989 to August 14, 2000 excluding FOMC meetings, days when the target was changed, and days for which $\left|E_{t-1}\left(\Delta f_{t}^{*}\right)\right|<0.125$. Observations: 184 . Standard Errors in parenthesis. Term rates measured in percentages. $*(* *)$ indicates significant at the $10 \%(5 \%)$ confidence level. 
Table 7 - The Response of Term Rates when the Target is Changed

$$
\begin{aligned}
& \Delta R_{\tau}=\alpha_{0}+\alpha_{f} d_{\tau}^{F O M C}+\alpha_{s} d_{\tau}^{\text {SWITCH }}+\beta_{1}^{0} E_{\tau-1}\left(\Delta f_{\tau}^{*}\right)+\beta_{1}^{f} d_{\tau}^{F O M C} E_{\tau-1}\left(\Delta f_{\tau}^{*}\right)+ \\
& \beta_{1}^{s} d_{\tau}^{\text {SWITCH }} E_{\tau-1}\left(\Delta f_{\tau}^{*}\right) d_{\tau}^{\text {SWITCH }}+\beta_{2}^{0} \widetilde{\varepsilon}_{\tau}+\beta_{2}^{f} d_{\tau}^{F O M C} \widetilde{\varepsilon}_{\tau}+\beta_{2}^{s} d_{\tau}^{\text {SWITCH }} \widetilde{\varepsilon}_{\tau}+u_{\tau}
\end{aligned}
$$

\begin{tabular}{|c|c|c|c|c|}
\hline & & $\Delta R_{t}=$ Repo & $\Delta R_{t}=3$-month T-Bill & $\Delta R_{t}=10$-year T-Bond \\
\hline \multirow{6}{*}{ Intercept } & $\alpha_{0}$ & 0.02 & 0.03 & $0.07^{* *}$ \\
\hline & & $(0.07)$ & $(0.03)$ & $(0.03)$ \\
\hline & $\alpha_{f}$ & -0.04 & -0.06 & $-0.11 * *$ \\
\hline & & $(0.10)$ & $(0.04)$ & $(0.04)$ \\
\hline & $\alpha_{s}$ & 0.04 & 0.00 & 0.01 \\
\hline & & $(0.10)$ & $(0.04)$ & $(0.04)$ \\
\hline \multirow{6}{*}{$\begin{array}{l}\text { Response to } \\
\text { Expectations }\end{array}$} & $\beta_{1}{ }^{0}$ & 0.16 & $0.23 *$ & $0.33 * *$ \\
\hline & & $(0.33)$ & $(0.12)$ & $(0.12)$ \\
\hline & $\beta_{i}^{f}$ & 0.16 & -0.11 & $-0.32 *$ \\
\hline & & $(0.44)$ & $(0.16)$ & $(0.16)$ \\
\hline & $\beta_{l}^{s}$ & -0.20 & -0.01 & 0.03 \\
\hline & & $(0.42)$ & $(0.16)$ & $(0.16)$ \\
\hline \multirow{7}{*}{$\begin{array}{l}\text { Response to } \\
\text { Surprises }\end{array}$} & $\beta_{2}{ }^{0}$ & $0.54 *$ & $0.74 * *$ & $0.44 * *$ \\
\hline & & $(0.31)$ & $(0.11)$ & $(0.11)$ \\
\hline & $\beta_{2}^{f}$ & -0.34 & -0.12 & $-0.67 *$ \\
\hline & & $(0.91)$ & $(0.34)$ & $(0.34)$ \\
\hline & $\beta_{2}^{s}$ & -0.01 & 0.46 & $1.71 * *$ \\
\hline & & $(1.71)$ & $(0.63)$ & $(0.64)$ \\
\hline & $\mathrm{R}_{2}$ & 0.23 & 0.70 & 0.42 \\
\hline
\end{tabular}

Sample: May 18, 1989 to August 14, 2000, only target changes included. Observations: 45. Standard Errors in parenthesis. Term rates measured in percentages. $*(* *)$ indicates significant at the $10 \%(5 \%)$ confidence level.

\section{Responses to the Surprise component}

\begin{tabular}{l|ccc}
\hline \hline Timing of Target Change & Repo & 3-month & 10-year \\
\hline At FOMC: $\beta_{2}{ }^{0}+\beta_{2}{ }^{f}$ & 0.20 & $0.62^{*}$ & -0.23 \\
& $(0.86)$ & $(0.32)$ & $(0.32)$ \\
Outside FOMC: $\beta_{2}{ }^{0}$ & $0.54 *$ & $0.73 * *$ & $0.44^{* *}$ \\
& $(0.31)$ & $(0.11)$ & $(0.11)$ \\
At FOMC + SWITCH: $\beta_{2}{ }^{0}+\beta_{2}{ }^{f}+\beta_{2}{ }^{s}$ & 0.19 & $1.08^{* *}$ & $1.48^{* *}$ \\
& $(1.47)$ & $(0.55)$ & $(0.55)$ \\
Outside FOMC $+\mathrm{SWITCH}: \beta_{2}{ }^{0}+\beta_{2}{ }^{s}$ & 0.53 & $1.19^{*}$ & $2.15^{* *}$ \\
& $(1.73)$ & $(0.64)$ & $(0.65)$ \\
\hline \hline
\end{tabular}

Standard errors in parenthesis. * (**) indicates significant at the $10 \%(5 \%)$ confidence level. 
Figure 1: A General Model of the Reserves Market with Anticipated Policy Actions

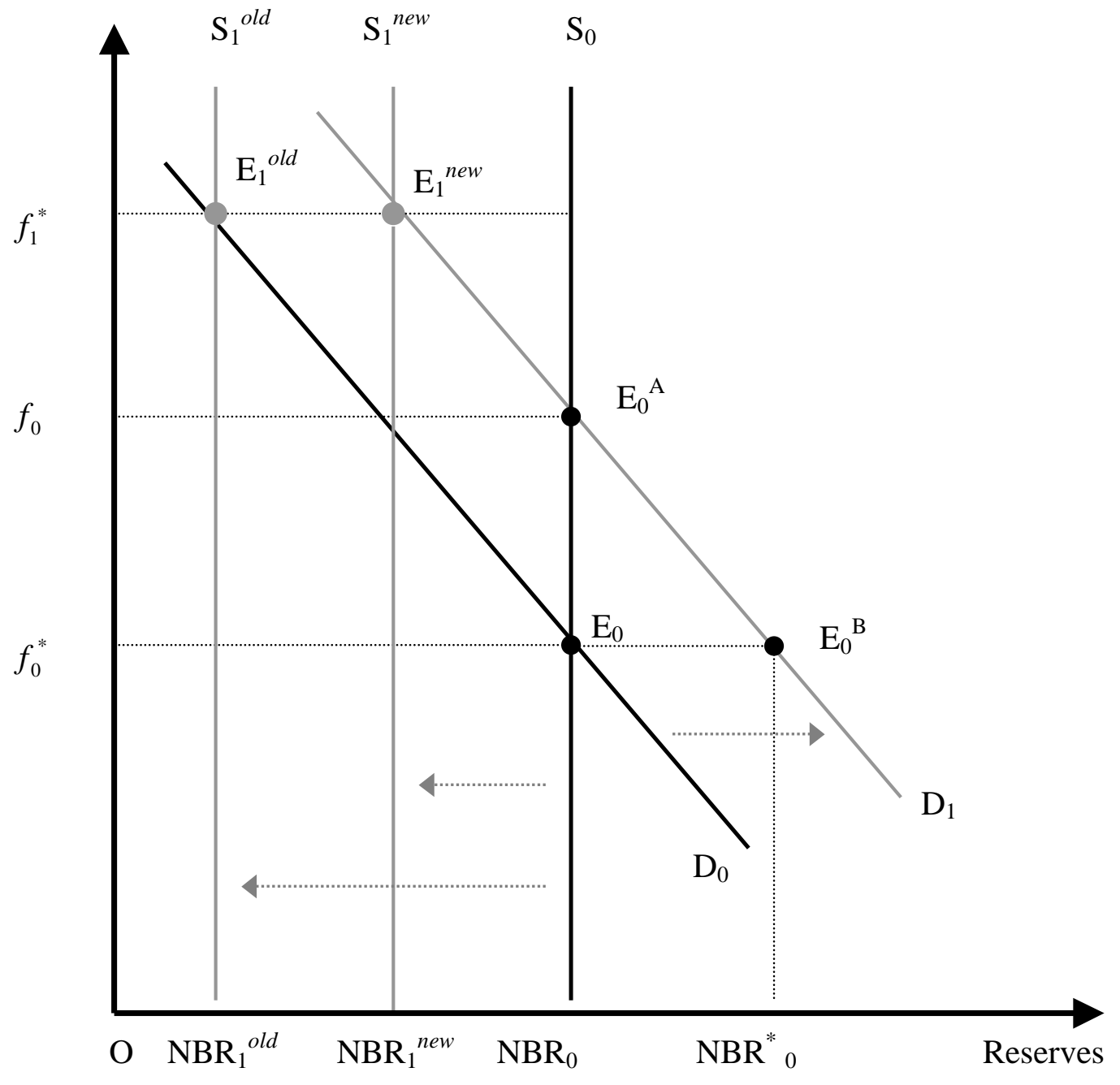


Figure 2 - Maintenance Period Pattern of Deviations of the Federal Funds Rate

\section{from Target}

Average Deviation of the Federal Funds Rate from Target

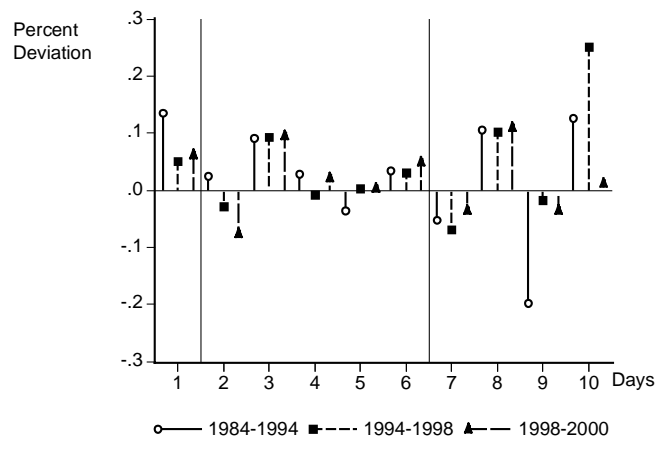

Persistence of the Deviaton of the Federal Funds Rate from Target
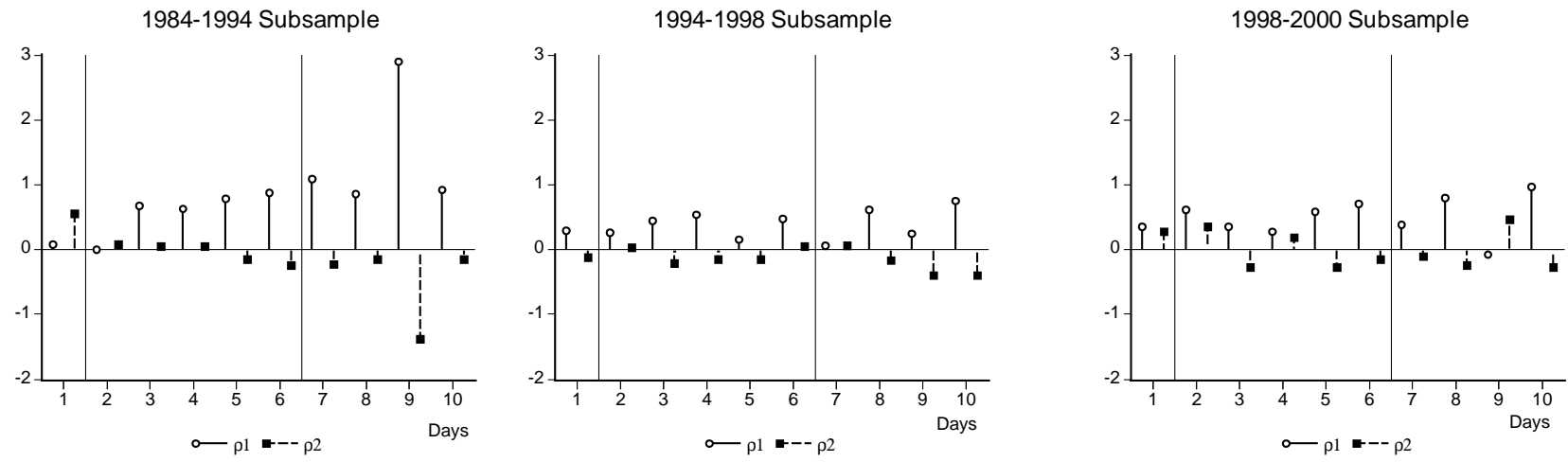

Note: shaded area corresponds to Fridays. 